\title{
Computer Support for Knowledge Management within R\&D and the Teaching of Bachelor Students
}

\author{
http://dx.doi.org/10.3991/ijet.v8iS1.2328 \\ Stefan Svetsky, Oliver Moravcik, Jana Stefankova, Peter Schreiber \\ Slovak University of Technology, Trnava, Slovakia
}

\begin{abstract}
Knowledge plays a key role within research, development and education. One of the major challenges for knowledge management is to select the right knowledge from numerous sources, including know - how of individuals, and to transform it into useful, practicable knowledge. The focus should always be on supporting strategic organisational goals. In this context, from the organisation's strategic point of view, it is very important to link an institutional knowledge management system with the knowledge management systems of individuals. This paper presents personalised IT - support for knowledge management within industrial $R \& D$ and especially for teaching and learning. The support is based on the use of a long term developed in - house software that enables individuals (managers and teachers) to process and manage knowledge on their desktop computers in a user friendly way. Within the implementation of "Technology - enhanced learning" at the Faculty of Materials Science and Technology, a pre programmed work environment called BIKE (Batch Information and Knowledge Editor) was developed. However, this desktop environment works also as a teacher's personalized knowledge management system. It is programmed by the lead author of this paper who is a teacher; therefore the outcomes into teaching bachelor students are implemented directly into the classroom. The paper also presents how such IT - support complements, at a personalized level, the existing organizational knowledge management tool known as the university's Academic Information System. Some examples from teaching are presented, communication channels (teacher - student forums) were also mentioned as a part of the teacher's knowledge management personalised system. In this case, the BIKE environment is demonstrated as an alternative to learning management systems based on the so called WEB 2.0 technologies.
\end{abstract}

Index Terms-component; knowledge management, knowledge management system, technology - enhanced learning, educational technology, computer assisted learning

\section{INTRODUCTION}

Knowledge management (KM) is a relatively new field that began to form in the 90's, especially in industry, following this it spread to the other sectors, including universities. During its development, IT tools for KM were also developed, such as the database technology in the form of information systems that worked on a companies' intranet at the beginning, then KM systems and other internet applications, e.g. eLearning tools, WEB 2.0 semantic approaches, grid technology, clouds with redepositories, etc. However, despite the huge IT progress, the basic
TABLE I. KNOWLEDGE MANAGEMENT ITEMS

\begin{tabular}{|c|c|}
\hline KM in Industry & KM in Education \\
\hline $\begin{array}{l}\text { Organisation - customer oriented } \\
\text { Technology - ICT } \\
\text { Solutions - production, services }\end{array}$ & $\begin{array}{l}\text { Organisation - student oriented } \\
\text { Technology - ICT } \\
\text { Solutions - teaching, learning }\end{array}$ \\
\hline
\end{tabular}

function of knowledge in KM is always the same. This means, the basic issue is still set to deliver, bring and provide the right knowledge to the right person at the right time and place. One of the major challenges is also to select the right knowledge and information from numerous sources and to transform it into useful, practicable knowledge (from an organisation's strategic point of view).

One must be aware, that KM is a set of activities and processes that are however always in relation to knowledge and about knowledge. Therefore, the solving of KM is commonly covered with more than one piece of software. In addition, the term knowledge includes various categories of knowledge. In the engineering education of bachelor students engineering knowledge is important. To develop successful KM - the software requires one to accept technical, organisational and solution know - how. This is illustrated in table 1 . There is a similarity of the $\mathrm{KM}$ function in industry and also its function in education. Logically, the focus and solutions are different. In both cases, knowledge plays a key role (essentially, students are "customers" of the teacher). KM is more about people than technology; however, the role of the technology is mainly to enable knowledge - sharing, or to support knowledge workers at an operational level. Despite the need to support strategic organisational goals, personnel KM tools (software) should be created and linked with the organisation's tools, i. e. the knowledge management system.

In the first case, database technology was adapted to the needs of the R\&D laboratory according to the immediate market requirements (2000 - 2005). Thus, the target was to survive, to be sustainable and competitive; the KM approach was customer oriented. In the second case, the IT support (2006 - 2012) was targeted on improving the quality of bachelors' teaching in order to eliminate the weaknesses in chemistry, English language and writing semester projects. In both cases the IT support for KM was subordinated and adapted to strategic objectives of the organisation's quality policy.

What should be emphasised, this was a bottom - up personalised concept. The in - house developed IT application was named by laboratory staff as WritingPad 
(Zapisnik) because "they wanted to write the technical and customer oriented notes in a shared work environment”. WritingPad was then further modified at the university within the bachelors' teaching. This resulted gradually in the development of the pre - programmed work environment of BIKE (Batch Information and Knowledge Editor).

\section{SOME AsPeCTS OF KNOWLEDGE}

Knowledge plays a key role within research, development, innovation and education. This affects individuals and a company's or university's level of the shared know - how. One must understand such terms as KM, KM systems, or the knowledge transfer, acquisition, creation, sharing, dissemination, conversion, etc. However, knowledge has different meanings from the various points of view belonging to knowledge management, information and communication, education or philosophy, where individuals need to have a large amount of knowledge at their disposal. One can understand Data as numbers, short strings (e.g. facts), Information as data put into context, and Knowledge as a set of information put into context with experience, judgement, skills and decision making. For example, in the Oxford Dictionary (http://oxforddictionaries.com), knowledge can be "the sum of what is known", "information held on a computer system”. This is very a good and understandable from a laic point of view.

Moreover, when working with knowledge it is linked to the mental processes of the human mind. This complicates IT support when treating knowledge as a significant personal and organizational resource. However, the issue of $\mathrm{KM}$ and IT approaches for KM and Learning is sufficiently described in the literature. One can obtain a quick overview from the resources in [1 - 5] in terms of knowledge and in [6 - 9] in terms of technology. In view of this paper, it is important that the so - called explicit knowledge can be written in various IT formats (e.g., technical documents, rules, standards, requirements - teaching texts and e - learning material). Therefore, they are easily transmittable. The second part of knowledge considered to be tacit (hidden) is essentially stored in the minds of managers, teachers and students. This tacit knowledge has great importance in business and education, especially when assuming it to be converted into explicit knowledge and shared for the benefit of an organisation. Despite the fact that some authors argue that, how it results already from the principle of their definition, the tacit knowledge cannot be fully captured and so converted to become explicit [4], the majority of researchers in KM consider a balance of tacit and explicit knowledge as a key to the success of the company.

To better understand this contribution one should know that this IT approach for KM in the R\&D laboratory and at the university was primarily solved on an empirical basis, i. e. without knowing that that such terms exist, such as: knowledge management, technology - enhanced learning or eLearning. The industrial stage, therefore, was understood as the processing of data and information. The starting point was, as mentioned above, that the laboratory staff wanted to work with texts and not only with testing data.

On the other hand, in real practice, one has to work with various categories of information and knowledge and one needs to process a vast quantity of this in one's daily work. After experiences obtained in industry with mass information processing, a similar approach regarding knowledge was needed. Due to this knowledge was defined as being a set of information that is structured and unstructured with a specified content stored in one row of the knowledge table and with a default structure [10]. This enables an individual (teacher, student, researcher) to utilize the huge power of database technologies and existing programming languages. In this context, the batch knowledge paradigm was formulated which is other than the conventional paradigm that uses a relation database model. More detailed information can by found in papers presented on conferences in the USA and Australia [10 $12]$.

Such a formulation of knowledge is not antagonising to any knowledge approach from an informatics or laics point of view. For example, this enables one to "make whatever" with knowledge, including converting tacit knowledge into explicit knowledge. So in our case, information is understood as the "most simple knowledge" and data as the "simplest information". Hence, in engineering education it is understandable enough that the most primitive knowledge can be understood 3,14 - 9,806 $\mathrm{m} \mathrm{s}^{-1}-1,6$ x $10^{-19} \mathrm{C}-6,023 \times 10^{23} \mathrm{~mol}^{-1}-96485 \mathrm{C} \mathrm{mol}^{-1}$ (the known constants).

In this context, BIKE works as a personalised system work environment for mass information and knowledge processing. Because there are many existing areas or processes based on using knowledge such an approach is universal. This means, the in - house developed system is suitable for the support of teaching and learning, selfstudy, knowledge management and decision making, etc. (everywhere if knowledge is used). For example, one must realise that $\mathrm{KM}$ is basically a set of procedures and processes. Therefore, it only depends on the individual user as to how one applies BIKE or WritingPad.

Regarding this, WritingPad was at the disposal of students performing diploma works. Some of them have produced eLearning or teaching material (e. g., a manual for Windows 7) or a personnel information system (for cutting fluids, occupational health and safety). One of them has solved the transfer of engineering texts (content) from printed scientific books - from before the Internet era, up till the teaching in the classroom with computers.

Now, when the participatory action research on technology - enhanced learning (TEL) is more systematic, it is also inspired by biochemical processes running in cells of living systems - but it is not any neural works approach. Hence, even if one can say, that BIKE is a personnel KM system, in reality this differs from other informatics tools described in literature for KM. However, due to its multipurpose functions, it covers many technological issues of KM.

\section{THE KNOWLEDGE MANAGEMENT IN IDUSTRY}

The application known as WritingPad was originally developed for information processing (KM) within an industrial R\&D laboratory. By using this application the laboratory's information system was developed and presented for auditors as evidence of a laboratory's documentation, management and control according to the standards of ISO EN 9001 and ISO EN 17025 (Figure 1). The system had approximately two thousand files. In this case, WritingPad worked as a supportive informatics tool for 


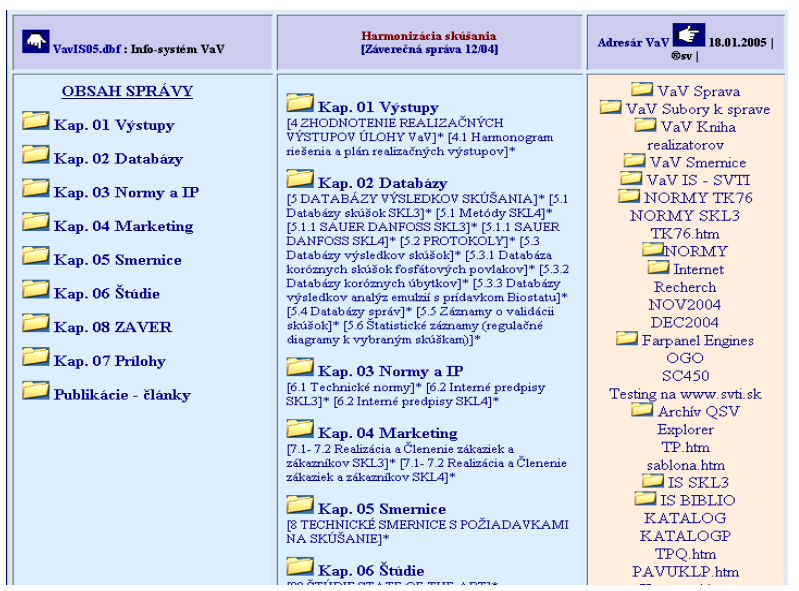

Figure 1. Navigation screenshot of the laboratory’s information system.

the conversion of tacit knowledge into explicit knowledge, and the recording and sharing of explicit knowledge within a customer oriented KM.

The function of a laboratory's KM is clearer from the screenshot in Figure 1. This comprises of icons for Outputs - Databases - Standards and Internal rules - Marketing - Directives - Publications, etc. (in 2004, this was the off - line KM system).

In the area of KM, a result is always important in order to show if the knowledge management approach was effective. In this case, the main role of this type of KM was to keep the laboratory sustainable and to be competitive. At the time, the Surface treatment department launched corrosion tests (e. g. STN ISO 9227 - NSS, VDA 621 - 415, VW PV 1210) and customers were mainly sub deliverers for the automotive industry or petrochemical companies. Thus, the strategic goal was focused on increasing the corrosion tests quality. This required the laboratory to transform the common KM level and focus it more on the customer needs, i. e. to also integrate customer knowledge into management process. Concurrently there was a specific problem related to corrosion tests' conditions and test reports, because the dealers of the automotive companies did not understand the issue of corrosion testing (however, they ordered tests by the laboratory). This meant that laboratory staff had to also study and understand technical documents and standards of companies.

To be sustainable and to fulfil all of the above mentioned requirements, basically, three categories of KM had to be continuously solved - KM for common managerial tasks (e. g. decision making, marketing), for corrosion tests issued, and for the integrating of customers' KM (language support, consultation tasks). The database application WritingPad worked as a support tool for all of the three KM categories. In this contribution, there is not enough space for describing the successful case study, however, in this case, by using the IT support (WritingPad) the laboratory with 5 to 7 people got from a common company's level to national and international R\&D projects, even to the $5^{\text {th }}$ Framework Programme EU (e.g., Corr \&Tests project proposal was submitted in 2000).

\section{TECHNOLOGY - ENHNACED LEARNING}

The further development of the application of WritingPad continued within the implementation of Technology - enhanced learning at the Slovak University of Technology - Faculty of Materials Science and Technology. This resulted in the development of the pre - programmed environment called BIKE (Batch Information and Knowledge Editor). For this purpose, the definition of knowledge was stated (suitable from the informatics and educational point of view) and a new paradigm for batch knowledge processing was formulated (the paradigm of batch processing is different from the conventional relational database).

Thus, knowledge is defined as a set of structured and unstructured information with a specified content stored in one row of the database table with a default structure. This approach allows for individual users to benefit from the power of the conventional relation database management system (RDBMS) and to work with huge amounts of knowledge just as with the rows of the database table, e. g. in order to automate a teacher's activities.

BIKE is programmed by the lead author of this paper who is a teacher; therefore the outcomes in teaching were implemented directly into classrooms. Thanks to this specialization, the results of these applications in teaching could gradually be presented at conferences focused on computer - enhanced engineering education within the USA (WCECS, ICEIC), Australia (AaeE) and the EU (ICL - IGIP, IGIP - SEFI, DAAM).

\section{A. The technology - driven phase of technology - enhanced learning}

The existence of the BIKE work environment enables the teacher to solve the first stage of processing the knowledge flow between information sources and the knowledge tables. The user outputs are directed both to the BIKE environment and to the browsable hypertext format - the default is set to Internet Explorer and Opera. During the previous five years, a virtual learning space with learning texts and libraries was created within the technology - driven phase of technology - enhanced learning. The further approach was then focused on the educational - driven approach. A personal social network teacher - students was programmed due to communication and feedback and a set of informatics tools were created for teaching support (e.g. virtual calculation of space - the chemical calculatrice).

In our case, the technology - driven approach is the bottom - up concept, because this approach was developed by the writing of programming codes primarily according to needs of researchers (in industry) or teachers and students (in university). For example, if they needed to work out (transfer) tacit or explicit knowledge the appropriate items were developed and added to the user menu. From an informatics point of view, this approach is presented in Figure 2, thus, as the teacher's KM system.

The mentioned personal social network is depicted as the triangle that links the teacher with students through communication channels. Each study course has its own channel. The virtual learning space is at the faculty's server. Nowadays, there is approximately five thousand various files in this space. This means that KM in education is also about how to organize and maintain many documents (this involves more files than was included in the above mentioned information system of the R\&D laboratory). 


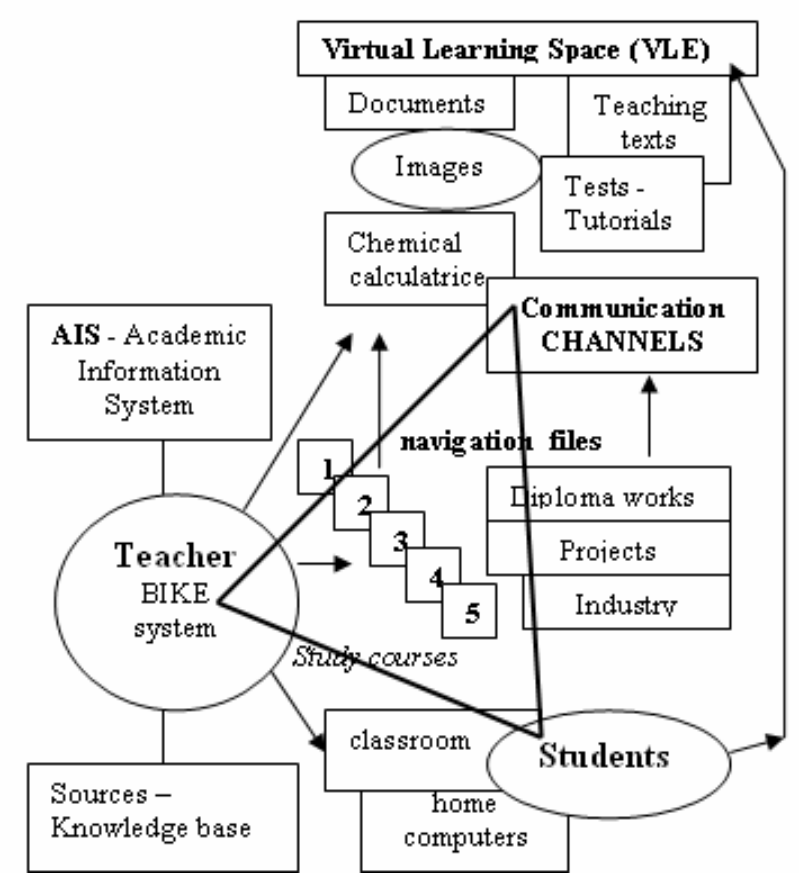

Figure 2. Teacher's personalised knowledge management system.

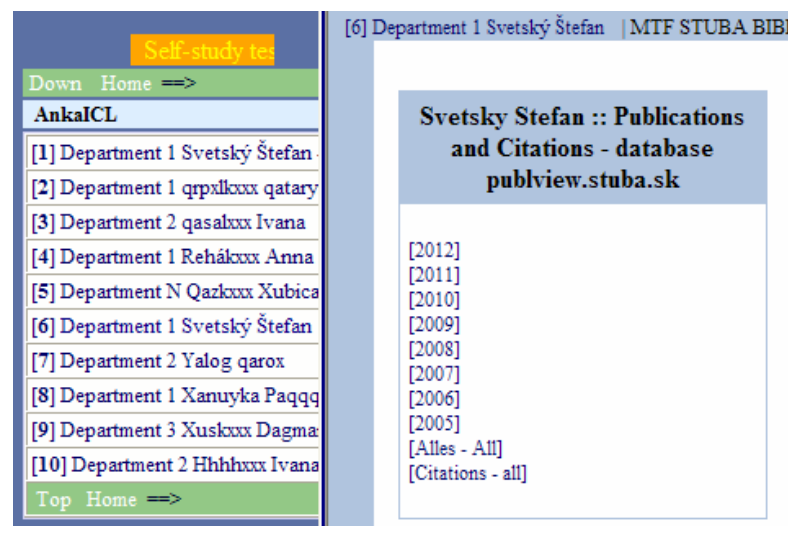

Figure 3. Linking BIKE with the university’s system about publications.

Another example of personalised KM using BIKE in a university's environment is illustrated in Figure 3. This shows how the lead author extracts published data from the university's database (this is suitable for higher management to have in order to view the publication performance of its staff). One can very quickly obtain information about one's own publications from the database in each year separately or as a summary (“Alles - All”).

\section{B. The educational - driven phase of technology - enhanced learning}

The empirical, so called participatory action research, has shown that the work of university teachers when using engineering knowledge is highly sophisticated. From an informatics perspective, this means that support of mental, learning activities and teaching is characterized by the use of unstructured information and knowledge. Thus, each type of learning activity should be studied, analysed (repeatability, elements, action sequences), this is the basis of the programming codes. In this case, there is an advantage that the researcher works both as the teacher and the programmer because one can write programming codes from the ground up for teaching bachelors according to their actual needs.

In this context, two elements come into play in practice. One is that the teacher has to select different didactic approaches (teaching methods) to address communication with students due to feedback. The second element is that it should be focused on the automation of all kinds of normal teaching activities, they are always consisting of sequences of sub - activities' steps. However, as the teacher plays a key role technology must adapt to his teaching, not contrary to this. This is the principle of any automation solution within TEL. Computer aided education should be focused on those two elements on both levels of educational quality and automation activities of the teacher and students. If we hold to technology - enhanced Learning, the priority must be given to the education (pedagogically) - driven, see the same conclusion in [6]. Therefore, the mechanical application of some existing general software (e.g., Learning Management System, so called Web 2.0 technologies) is not possible.

In practice, only the bottom - up concept could reveal in teaching practice that the "dead" teaching material stored on the internet or computers must be "revived" by a teacher in the classroom. Hence, by the solving of the education - driven approach for TEL, it was needed to be enlarged by programming communications channels, so called study courses' Forums. This means that the integration of both teaching instructions and teaching materials into these channels was a necessity for each course of study. Figure 4 and Figure 5 show how it works.

For example, the arrows between the "TEL" - information sources on the university server and study courses illustrate the way of this integration. As depicted, there are several categories of the sources, i. e. teaching texts, documents (files), tools, calculation area and also tests. These are on the internet and other Knowledge base sources can also be stored in the knowledge tables of the mentioned BIKE environment. Another arrow from the study course 4 to study course 5 illustrates that, e.g., written by a student from the study program Programming language (an exe - file written in $\mathrm{C}++$ language) was then used by students from other bachelor course of study in writing semester works. In other words, the student has participated in the preparation of teaching material. From an educational point of view, the channels work as teaching tools and from a KM point of view, they work for the conversion, transfer and sharing of tacit and explicit knowledge.

Figure 4 illustrates the knowledge flow through communication channels of the five courses of study (Chemistry, Environmental protection, Occupational health and safety, Programming language and Semester projects), as well, through the channels dedicated for diploma works, or for a teacher's collaboration in projects together with industry.

Figure 5 illustrates in detail some content of one of the communication channels between a teacher and students writing diploma works. It illustrates examples of shared retrieval results (on the top), internet outputs from diploma works (in the middle) and an area with instructions and information exchange (at the bottom). 


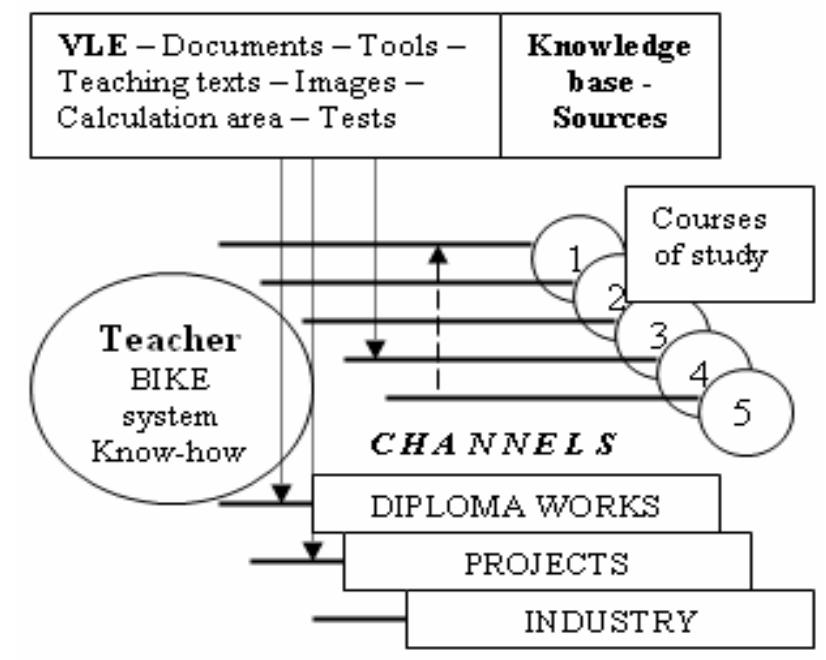

Figure 4. The knowledge flow through communication channels.

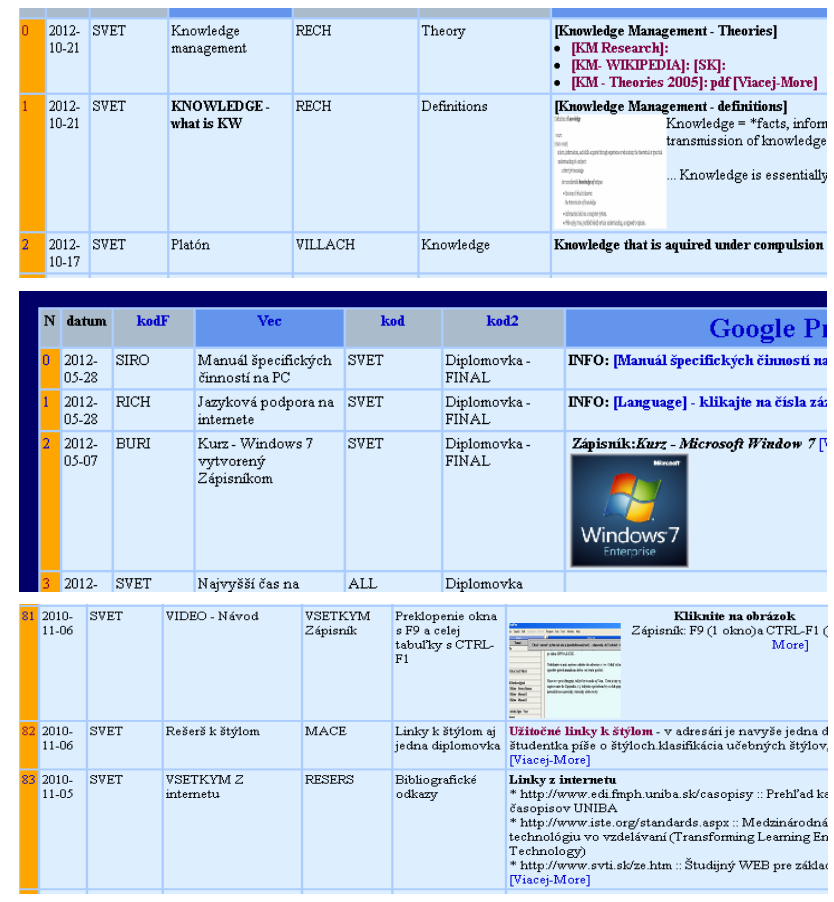

Figure 5. Example of the content of the communication channels between teacher and students writing diploma works.

Figure 6 shows another example of teaching material generated by BIKE. In this example, firstly, virtual chemical calculatrice was selected using this material, then when clicking on the calculatrice students could calculate and train the Nernst equation (Electrochemistry).

Figure 7 shows another category of using BIKE for the assessment and grading of students by the teacher. In this case, the teacher has transferred students' data from the university's Academic Information System into one's work environment, then assigned points for each student (top), then selected from the user menu the calculation and HTML options and finally has obtained browsable results (down).

The importance of such a personal approach for KM is also emphasised in the actual literature, e.g., in an exploratory study related to roles and values of personal knowledge management [13]. This paper can also be understood as a contribution to be beyond such ap-

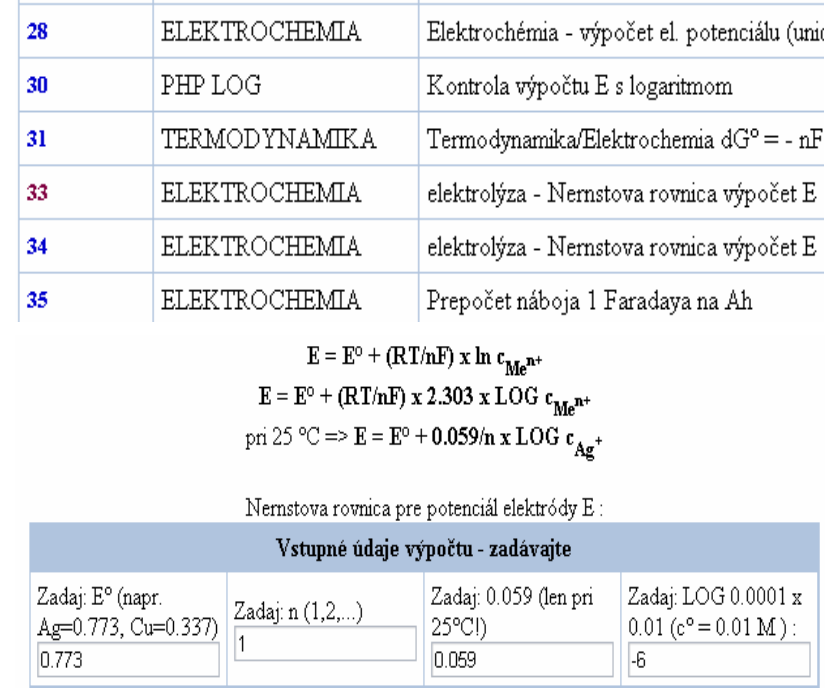

Chemia: Vykonaj

Figure 6. Example of the teaching material and chemical calculatrice for the study course of Chemistry.

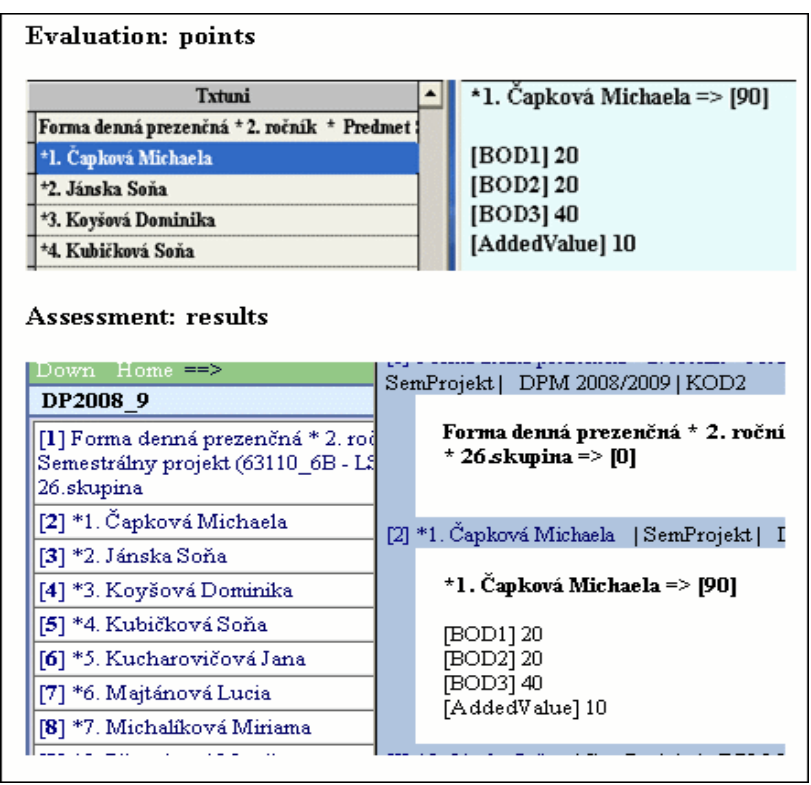

Figure 7. Linking BIKE with the Academic Information System.

|!!YINE: The journal of information and knowledge manageme Britannica Knowledge - Wisdom nie je Innate (vrodená) and ag !!! The DIKW hierarchy Creation of knowledge !!!

Data Mining

VINE: The journal of information and knowledge management

Journal of Organizational Change Management

Anti-Corrosion Methods and Materials

Journal of Knowledge Management

Management Merisinn

Figure 8. Example of teachers' personal notes from retrieval.

proaches, such as a personal learning environment [14]. Maybe, just another example should be given to better understand the teacher's role and issues in KM, as shown in Figure 8.

More examples could be presented from the portfolio of outputs into teaching and learning in bachelors' engineer- 


\section{SPECIAL FOCXUS PAPER}

\section{COMPuTER Support FOR KNOWLEDGE MANAGEMENT WITHIN R\&D AND THE TEACHING OF BACHELOR STUDENTS}

ing teaching, including support for self - study, decision making, technical language teaching, blended learning, active learning, etc. However, the above mentioned examples should be enough to demonstrate the importance of building a KM approach from the teacher's point of view in such organisations as universities. It should be also mentioned, in this context, that the KM issue is more complex than as it is stated in the existing ICT terminology. For example, the described personalised approach for KM performed by the BIKE can also cover other issues such as personal learning environments, educational data mining, decision making and educational software, etc. For example, Figure 9 shows one such example from the analysis of the structure of keywords in the joined ICL IGIP conference which was held in Villach, Austria [15]. The "educational data mining" analysis resulted into "knowledge" where the frequency of the occurrence of keywords in more than two hundred contributions was very low. In other words, a very large amount of key worded categories were found.

\section{CONCLUSIONS}

The computer support for the knowledge management within R\&D and Education when using the in - house software BIKE, as a personalised work environment, was briefly described. In both cases (R\&D laboratory, faculty's department) this resulted in increasing the organisational quality level, i. e. from an organisation's units which operated on the common level to the international R\&D level.

In this paper, especially the approach for KM and learning, it was explained on the basis of a practical solution for balanced education - driven and technology - driven approach in technology - enhanced learning, including the presentation of several examples from teaching in a classroom with computers. The function of communication channels within engineering courses of study (teacher student forums) was mentioned as a part of the teacher's personalised KM system. These channels were programmed due to the need to revive the "dead" learning material in virtual learning space or a knowledge database and to solve educational aspects based on the automation of teaching processes.

Such an approach within the bachelors teaching practice enabled the teacher to implement new innovative teaching methods, or students to participate directly in the research on computer assisted learning. What is important is that the processing of tacit and explicit knowledge and organisation of it by BIKE enabled the teacher to link his

\begin{tabular}{|l|}
\hline control engineering education; remote laboratories; client server application;three-lerel hydrulic system \\
course description; learning outcomes; assessment; grading; ECTS; alignment; curricula design; EQF. \\
\hline critical thinking, deep understanding, engineering education, teaching models, teaching strategies. \\
\hline distance learning; didactical model; self-assessment quizzes;feedback; learning curres; case study \\
\hline dynamic system; differential equation; Generalized Riemann integral \\
e-Assessment, Assesesment Model, Expert Validation, Complex Learning Ressouces \\
\hline e-Assessment; ontology; ralidation; item generation \\
\hline e-Learning, programming language, cryptography, teaching, algebra, computer algebra system \\
\hline e-assessment; dynamic assessment; serious games; feedback; game-based learning; intuitive guided lear \\
\hline e-tutor, blended learning potentials, blended learning analysis, course eraluation, sustainability, Moodle \\
\hline eLearning, cloud, Migration, eNcephalon \\
\hline educational software, optical communications, semiconductor lasers, laser rate equations model, frequen \\
\hline educational planning; teaching innoration; mechanical engineering. \\
\hline education projects, innoration in education, international seminars, computer science master degree \\
\hline
\end{tabular}

Figure 9. Example from the analysis of the structure of keywords (ICL - IGIP conference in Villach, 2012 ) - BIKE environment. personal KM system with the university's learning and management system (this also supports a teacher's decision making). Due to this in - house IT support for KM and knowledge construction being based on the automation of "working with knowledge", the next research on the personalised KM will be a "never -ending” story.

\section{REFERENCES}

[1] E. A. Smith, "The role of tacit and explicit knowledge in the workplace," Journal of Knowledge Management, vol. 5, Issue 4, pp. 311- 321, 2001. http://dx.doi.org/10.1108/1367327011 $\underline{0411733}$

[2] C. Reilly, "The Concept of Knowledge in KM: a Relational Model,” The Electronic Journal of Knowledge Management, vol. 7, Issue 1, pp. 145 - 154, 2009, available online at www.ejkm.com

[3] R. T. Herschel, H. Nemati, D. Steiger, "Tacit to explicit knowledge conversion: knowledge exchange protocols," Journal of Knowledge Management, vol. 5 Issue 1, pp.107 - 116, 2001. http://dx.doi.org/10.1108/13673270110384455

[4] H. Tsoukas, "Do we really understand tacit knowledge?,” Oxford: Blackwell. The Blackwell handbook of organizational learning and knowledge management, vol. 14, Issue 21, p.p. $410-427$, 2003.

[5] T. Haldin - Herrgard, "Difficulties in diffusion of tacit knowledge in organizations," Journal of Intellectual Capital, vol. 1 Issue 4, pp. 357 - 365, 2000.

[6] P. S. Goodman, “Technology Enhanced Learning: Opportunities for Change,” Lawrence Erlbaum Associates, Inc.. USA, 2001, 336 p. (books.google.com, routledge, 2002).

[7] J. Derry, “ Technology - Enhanced Learning: A Question of Knowledge,” Journal Philosophy of Education, vol. 42, pp. 505 519, 2008. http://dx.doi.org/10.1111/j.1467-9752.2008.00638.x

[8] R. Saljö, "Digital tools and challenges to institutional traditions of learning: technologies, social memory and the performative nature of learning,” Journal of Computer Assisted Learning. Special Issue:'CAL'-Past, Present and Beyond, vol. 26, Issue 1, pp. 53 - 64, February

2010.

[9] D. Laurillard, "Technology Enhanced Learning as a Tool for Pedagogical Innovation,” Journal of Philosophy of Education, vol. 42: pp. 521 - 533, 2008. http://dx.doi.org/10.1111/j.14679752.2008.00658.x

[10] S. Svetsky, O. Moravcik, D. S. Daynier, J. Stefankova, ”The Implementation of the Personalised Approach for Technology Enhanced Learning," Lecture Notes in Engineering and Computer Science, vol. 2186, Issue 1, pp. 321 - 323, 2010. [World Congress on Engineering and Computer Science. San Francisco, USA, 2010].

[11] O. Moravcik, S. Svetsky, F. Hornak, R., D. S. Daynier, J. Stefankova, "Experiences with the Personalised Technology Support for Engineering Education,” in 21st Annual Conference of the Australasian Association for Engineering Education \&2010 Fall CDIO Collaborators' Meeting, AaeE Conference, Sydney, pp. 532 - 538, December 2010.

[12] S. Svetsky, O. Moravcik, P. Schreiber, J. Stefankova, “ The Informatics Tools Development and Testing for Active Learning,” Lecture Notes in Engineering and Computer Science, vol. 2193, Issue 1, pp. 265 - 268, 2011 [World Congress on Engineering and Computer Science. San Francisco, USA, 2011].

[13] Ricky K. F. Cheong, Eric Tsui, “The roles and values of personal knowledge management: an exploratory study,” Journal of Knowledge Management, vol. 40, IssFehler! HyperlinkReferenz ungültig.ue 2, pp. 204 - 227.

[14] G. Attwell, "Personal Learning Environments - the future of eLearning,“ Journal: eLearning Papers, vol. 2, no. 1, pp. 1 - 8, 2007.

[15] 15th International Conference on Interactive Collaborative Learning and 41st International Conference on Engineering Pedagogy, Villach, Austria, 26 - 28 September 2012, 


\section{AUTHORS}

Stefan Svetsky, Oliver Moravcik, Jana Stefankova, and Peter Schreiber are with the Faculty of Materials Science and Technology in Trnava, Slovak University of Technology, Trnava, Slovakia (stefan.svetsky@stuba.sk, oliver.moravcik@stuba.sk, jana.stefankova@stuba.sk, peter.schreiber@stuba.sk)

This article is an extended and modified version of a paper presented at the International Conference on Interactive Collaborative Learning (ICL2012), held 26 - 28 September 2012, in Villach, Austria. 